\title{
New Type of Linear Switched Reluctance Generator for Wave Energy Applications
}

\author{
Luis García-Tabarés, Marcos Lafoz, Marcos Blanco ${ }^{\circledR}$, Jorge Torres ${ }^{\circledR}$, Diego Obradors, Jorge Nájera, \\ Gustavo Navarro, Francisco García, and Andres Sánchez
}

\begin{abstract}
Wave energy conversion is a promising alternative to produce clean energy from the huge available resource at sea, but it is also a challenging mission because extraction conditions are difficult due to the harsh environment and also to the low frequency of the energy conversion process. In this regard, powerful Power Take-Offs are required, able to produce high forces at low frequencies, which also must be highly controllable to optimize the conversion process. This paper presents a new type of Linear Electric Generator based on a novel Switched Reluctance Machine, which is being developed in the framework of a $\mathbf{H 2 0 2 0}$ Project called Sea Titan. The paper describes the calculation and the design processes of a $70 \mathrm{kN}$ prototype which will also be manufactured and tested in the framework of Sea Titan, which also includes a feasibility study for a superconducting solution.
\end{abstract}

Index Terms-Linear switched reluctance machines, power take off, wave energy converters.

\section{INTRODUCTION}

$\mathbf{E}$ UROPE'S 2050 Energy Strategy has established a target to reduce greenhouse gas emissions by $80 \%-95 \%$ compared to 1990 levels and renewable energy accounting for at least 64\% and up to $97 \%$ of the electricity consumed [1]. In line with these targets, the Ocean Energy Forum (OEF) produced the Ocean Energy Strategic Roadmap (November 2016) that has estimated that $100 \mathrm{GW}$ of ocean energy capacity could be deployed in Europe by 2050, producing around 350TWh of electricity meeting up to $10 \%$ of Europe's demand by 2050. For this target to be attained it is essential the development of wave energy and specifically the Power Take-Off (PTO) as one of the key technological priorities for wave energy converters, increasing the reliability and performance of ocean energy devices, as clearly stated by the EU Joint Research Centre in the 2016 Ocean Energy Status Report.

Most recently, the inclusion of ocean energy in the new SET-Plan of the European Union has highlighted the current European leadership in the sector. In line with the SET-Plan communication, the European Commission, Member States

Manuscript received September 19, 2019; accepted March 12, 2020. Date of publication May 14, 2020; date of current version May 27, 2020. This work was supported by European Union's Horizon 2020 Research \& Innovation Programme under Grant Agreement 764014. (Corresponding author: Luis García-Tabarés.)

Luis García-Tabarés, Marcos Lafoz, Marcos Blanco, Jorge Torres, Diego Obradors, Jorge Nájera, and Gustavo Navarro are with CIEMAT 28040, Madrid, Spain (e-mail: luis.garcia@ciemat.es).

Francisco García and Andres Sánchez are with WEDGE GLOBAL, 35017, Las Palmas de Gran Canaria, Spain.

Color versions of one or more of the figures in this article are available online at https://ieeexplore.ieee.org.

Digital Object Identifier 10.1109/TASC.2020.2981900

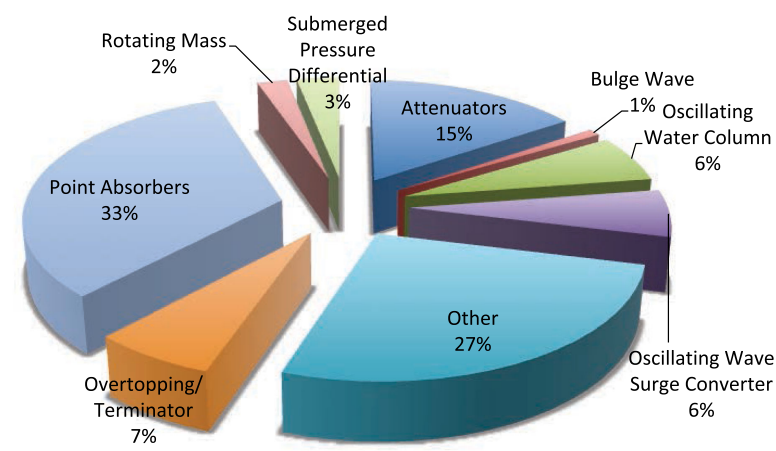

Fig. 1. Distribution of WEC technologies.

and stakeholders have defined cost-reduction targets for ocean energy technologies to make a significant contribution to the future European energy system [2]. The main focus of this Declaration for wave energy is to achieve $10 \mathrm{GW}$ of installed capacity by reducing the Levelized Cost of Energy (LCoE) by approximately $50 \%$ to $20 \mathrm{cEUR} / \mathrm{kWh}$ from present levels for similar sites by 2025. These favourable perspectives together with a consolidated experience in the field of linear Power Take Offs encouraged us to prepare a proposal for a 2017 H2020 call [3], which was successfully awarded. The project has been named Sea Titan, it has 11 participants, including 4 wave energy technology developers as potential users of this device. It is aimed at improving some relevant figures of merit of the PTO such as its Force Density, the Float to Wire Efficiency, the Capex Cost per $\mathrm{kW}$ or the $\mathrm{LCoE}$.

\section{BACKGROUND: HeAving POINT ABSORBERS}

Since the early days of the first consistent and scientifically supported proposals for producing electricity from the energy of the ocean waves up to nowadays, a great number of worldwide developments have been carried out, based on many different approaches. There are different publications [4], [5], [6] sorting and describing the working principles of these Wave Energy Converters (WEC). In 2017 the authors analyzed the information provided by the European Marine Energy Centre about 226 existing developments and systems for extracting energy from the wave [7].

Fig. 1 summarizes the results in terms of number of developments associated to 9 different technologies for WECs. As it can be seen, the most numerous types are the so-called Point Absorbers, a kind of omni-directional converter that is based on the relative movement of two bodies mechanically coupled 


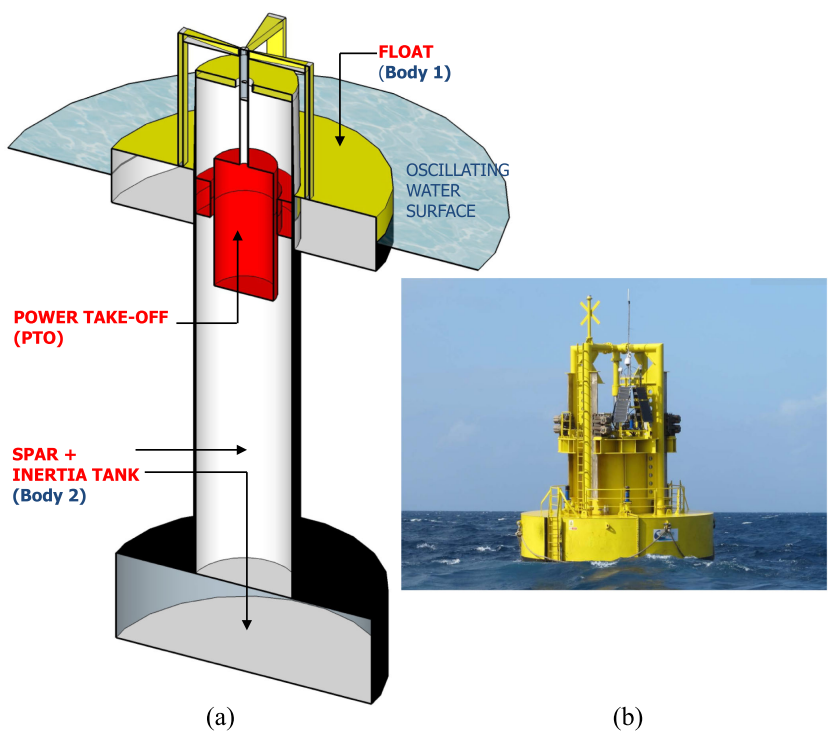

Fig. 2. (a) The concept of a Heaving Point Absorber. (b) Heaving Point Absorber deployed by WEDGE GLOBAL in 2014.

through a PTO. For the particular case of a vertical movement (heaving), linear generators are particularly suitable as PTOs, since they are able to convert mechanical energy into electricity in a single stage, with an intrinsic much better efficiency than any other type of PTO [8].

Fig. 2(a) shows the concept of a Heaving Point Absorber (HPA) and its three basic elements [5], [9]: The Float, with an oscillating resonant frequency close to the dominant wave frequency in the site where the HPA operates, the Spar and the Inertia Tank, with a much lower resonant frequency and a PTO linking the two previous elements. Eventually, the Spar can be mechanically connected to the sea floor.

The HPA can be modeled as shown in Fig. 3(a) with components corresponding to inertia, buoyancy, damping, radiation and external forces like the wave force or the PTO force [10]. For the simplified case of a single moving body HPA and regular and sinusoidal waves, the model has an equivalent electric circuit [11] represented in Fig. 3(b), with two voltage sources (Wave and the PTO forces, respectively) coupled through the characteristic impedance of the HPA, Z, which includes an inductance (mass) a capacitor (buoyancy) and a resistor (damping $\&$ radiation). The current represents the vertical speed of the moving part. It is also included a parallel resistor with the source, corresponding to the PTO losses.

This circuit allows determining the optimum force at the PTO to extract the maximum power from the wave.

The main conclusion is that "vector" force is required, meaning that the PTO force must be controllable either in modulus and phase. The PTO, hence, must produce a force with "active" and "reactive" components: the first being in phase with velocity (the one able to produce energy) and the second in quadrature with it.

Linear Electric Machines are ideal for this mode of operation; their main limitation in comparison with their hydraulic counterparts is their smaller total force capacity as well as the smaller force per unit mass. Different types of Linear Generators have been proposed for this application, [12]-[18] some of which are based on Self-Excited Machines using Permanent Magnets

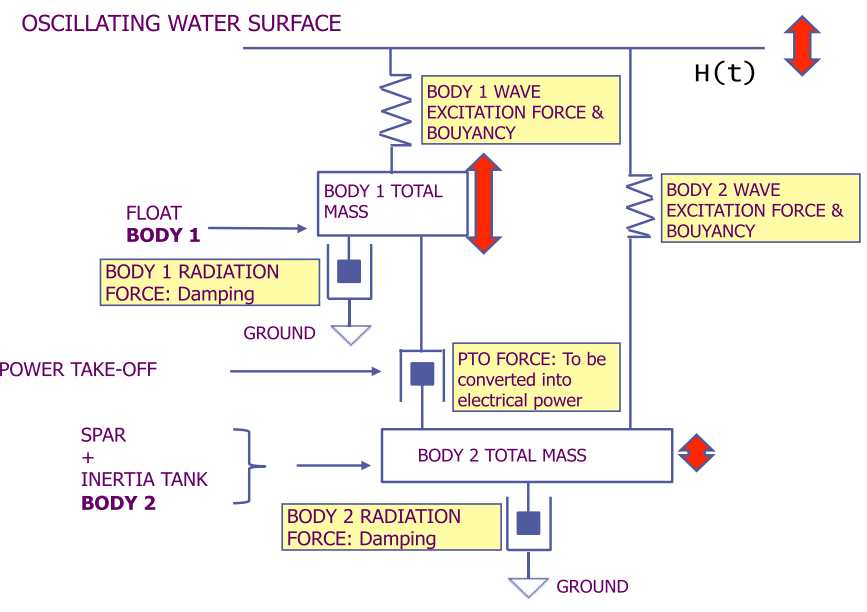

(a)

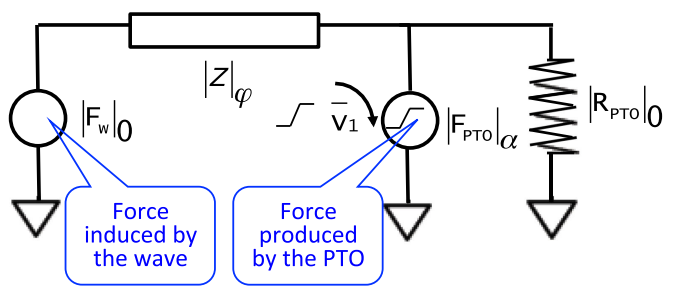

(b)

Fig. 3. (a) Mechanical Model of a two-body HPA. (b) Equivalent Electric Circuit of a Single-Body HPA.

with different configurations while others are based on non Self-Excited solutions like the one chosen for the Sea Titan Project whose main goal is to develop a new configuration of Linear Switched Reluctance Machine (LSRM) aimed at achieving higher specific forces and efficiencies. The conceptual study of a Superconducting version of a LSRM is also included in the Project.

\section{The AZImuthal Multi-Translator Switched RELUCTANCE MACHINE (AMSRM)}

The concept of Multi-translator Switched Reluctance Machine was introduced and patented some years ago when the company Wedge Global developed a Switched Reluctance Machine [19], [20] shown in Fig. 4(b) and based on the idea represented in Fig. 4(a).

The concept is quite simple: Adding additional inner stators and translators to a conventional double-sided Switched Reluctance Machine. Each new stator increases the force developed by the machine proportionally to the number of stators, but the overall weight of the machine is increased in a much smaller proportion, since they lack of the corresponding return yoke section to close the magnetic circuit as shown in Fig. 4(a) in dotted lines.

The previous machine still needs two lateral heavy stators with return yoke, which have a significant contribution to the overall weight. A step forward in this concept is the Azimuthal

Multi-translator Switched Reluctance Machine, which can be depicted in Fig. 5(a) for a single phase. The idea is to arrange the stator coils (active side) and the translator poles (passive side) circumferentially in a kind of toroidal geometry. Fig. 5(b) shows 


\section{(1)}
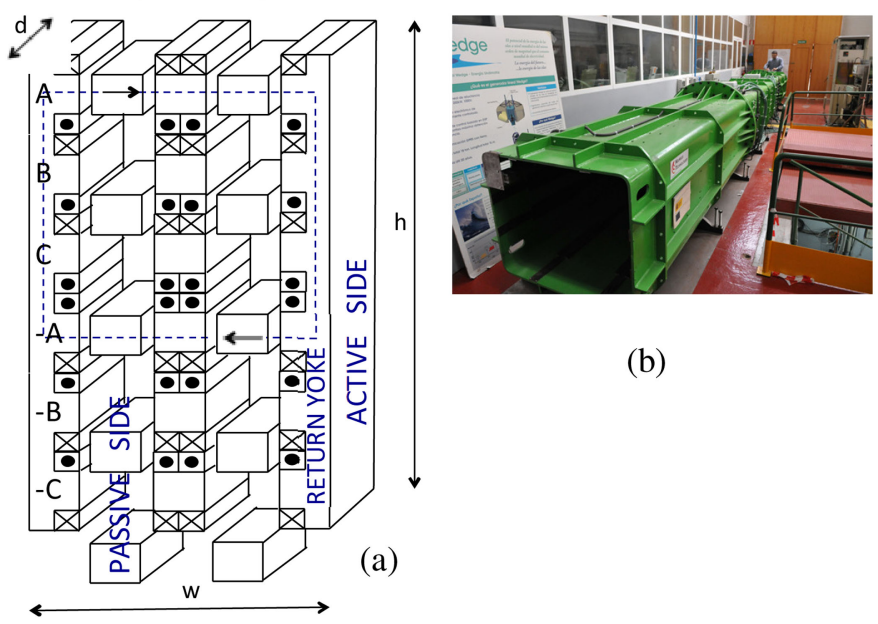

(b)

Fig. 4. (a) The concept of a 3 Phase Rectangular Multi-translator Switched Reluctance Machine (RMSRM). (b) The W-200 RMSRM type Generator developed by Wedge, while being tested at CIEMAT.

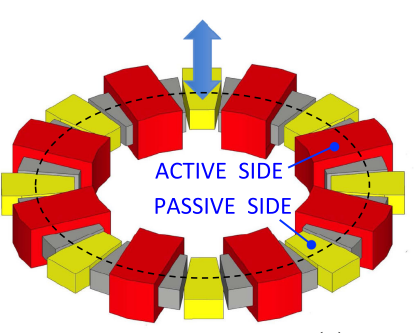

(a)

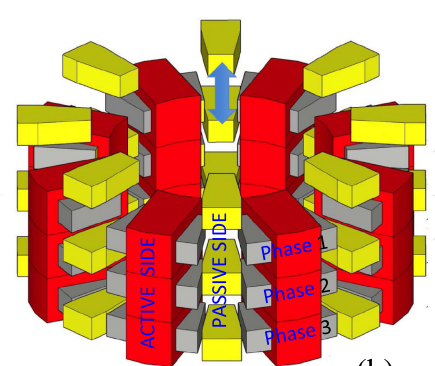

(b)
Fig. 5. (a) The concept of Azimuthal Switched Reluctance Machine. (b) Arrangement for a three-phase configuration.

the required arrangement for a three-phase machine configuration.

This solution has several advantages over the previous machine:

- There are no lateral stators and the required amount of iron is minimum (no need for return yoke) increasing the specific force.

- The leakage flux is smaller than in the rectangular configuration, so more force per ampere-turn can be achieved than in the equivalent rectangular multi-translator SRM.

- Its circular arrangement is more suitable for fitting in the standard cylindrical shape of a HPA.

The main goal of the H2020 Project mentioned in the introduction is to develop a prototype of an AMSRM and to test it at CIEMAT premises. Next paragraphs will be devoted to describe the work done so far, which concentrates on the calculation and design of the machine.

\section{A. AMSRM Calculation}

The most important calculations are the magnetic ones, since they are the basis for the rest (electrical, mechanical and thermal) [21]. They have been performed based on the following methodology: A simple 1-D analytical model, which takes into account iron saturation, has been developed to perform a pre-dimensioning of the machine. It is based on the idea of

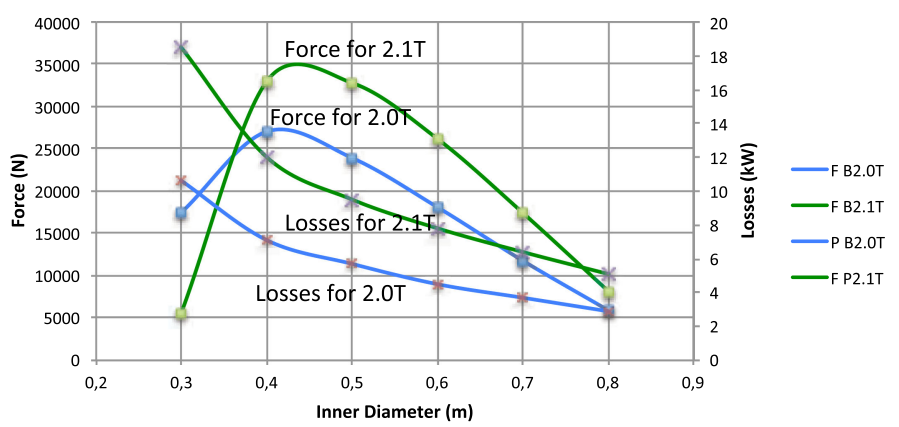

Fig. 6. Force and Losses as a function of the inner radius, for a $1 \mathrm{~m}$ Outer Diameter AMSRM Prototype, calculated with the 1-D Model.
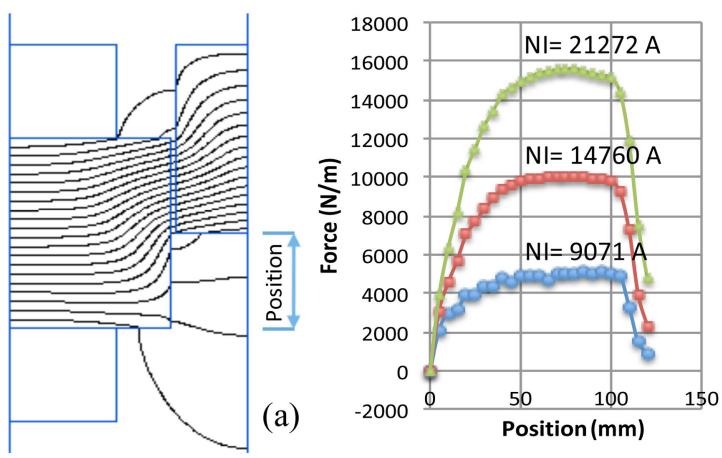

Fig. 7. (a) Field mapping in an AMSRM pole (b) Force (per meter depth) distribution between Active and Passive Sides as a function of their relative position for the geometry shown in (a) and 3 different values of ampere-turns.

replacing the active side coils with filamentary currents placed in the airgap. This allows an easy determination of the magnetic flux distribution and also of the force calculation. The model accuracy has been improved introducing corrector coefficients, which are calculated using a 2-D FEM code (Quick Field) run for some benchmark cases. Fig. 6 shows a preliminary optimization of the machine prototype based on this model. It considers a $1 \mathrm{~m}$ outer diameter machine calculating, for two selected values of magnetic flux density in the airgap, the force and losses for different inner diameters.

The 2-D FEM code calculation is based on the simplification that the machine is linearly developed along a tangential plane and allows calculating the force distribution between active and passive sides as a function of their relative position.

This kind of analysis shows the relevance of the coil aspect ratio (height respect to pole width) regarding leakage flux and consequently force distribution. Low aspect ratio coils drive to a triangular distribution with a low average force value, while high aspect ratios lead to rectangular distributions as the one shown in Figs. 7(a) and 7(b) with high average force values.

Once the first pre-dimension is performed with the previously defined tools, a precise optimization was performed using two 3-D codes: Opera from Dassault Systems and Maxwell from Ansys. Different magnitudes have been selected running the code, being, perhaps, the most sensitive one the wedge angle $\alpha$, as defined in Fig. 8(a). Fig. 8(b) shows the force distribution as a function of the relative position Active Side VS Passive Side for: a) the 1-D Model, b) QuickField and c) Opera for two pole wedge angles. As it can be noticed, the smaller the angle, the highest force distribution is achieved.

Running the 3-D FEA allows calculating the required parameters for the electric simulation of the machine connected to 


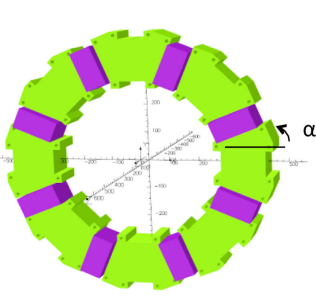

(a)

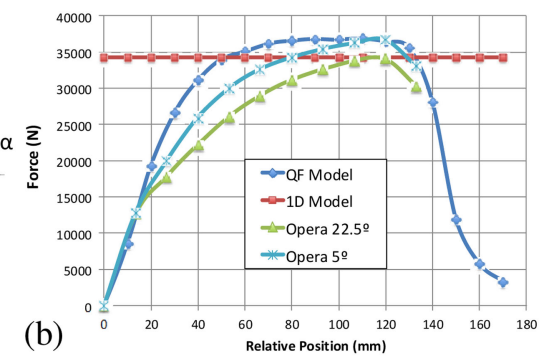

(b)

Fig. 8. (a) 3-D Opera Model of the AMSRM Prototype with the definition of the wedge angle $\alpha$. (b) Force variation with the relative position provided by Opera, QuickField and the 1-D Model.

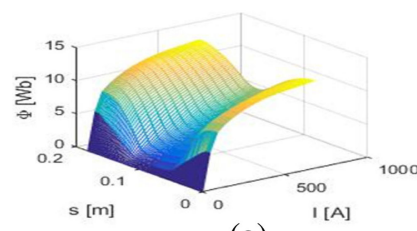

(a)

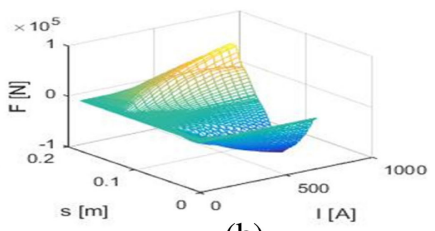

(b)

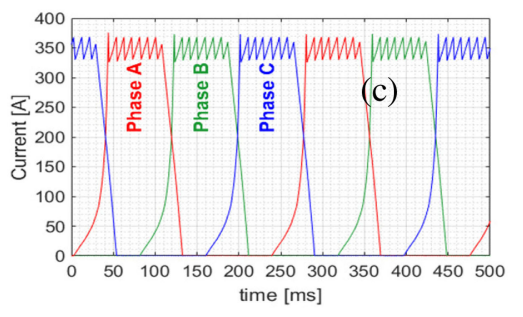

Fig.9. (a) Flux calculation per phase as a function of the current and the relative position (b) Overall Force calculation for the same variables. (c) Simulation of the phase current evolution based on the generator electrical equations and the magnetic calculations.

TABLE I

PARAMETERS OF THE AMSRM PROTOTYPE

\begin{tabular}{lc||lc}
\hline \hline \multicolumn{1}{c||}{ Parameter } & Value Units & Parameter & Value Units \\
& & & \\
\hline Number of Phases & 3 & Maximum Force & $70 \mathrm{kN}$ \\
$\mathrm{N}^{\circ}$ of Coils/Phase & 8 & Operational Current & $350 \mathrm{~A}$ \\
Outer Diameter & $1000 \mathrm{~mm}$ & D.C. Bus Voltage & $1000 \mathrm{~V}$ \\
Inner Diameter & $440 \mathrm{~mm}$ & Pole Ratio & $6: 4$ \\
Stroke & $\pm 3000 \mathrm{~mm}^{-1}$ & & \\
Maximum Speed & $3 \mathrm{~ms}^{-1}$ & \\
Active Side Config. & \multicolumn{2}{c}{ Moving, Inner \& Short } \\
\end{tabular}

its power converter. Since it is a Non Self-Excited Machine, its Converter must be fed from a DC bus, which is either connected to the grid through a Grid-Side Converter for grid-connection mode or which includes a battery or any other energy storage system, when working in stand-alone operation.

Magnetic Flux and Force for different values of current and relative position as shown in Figs. 9(a) and 9(b), are used to compute the current in each phase of the machine. Fig. 9(c) shows the current pattern when working in hysteresis band mode. Table I summarizes the main parameters of the prototype under development within the Sea Titan Project.

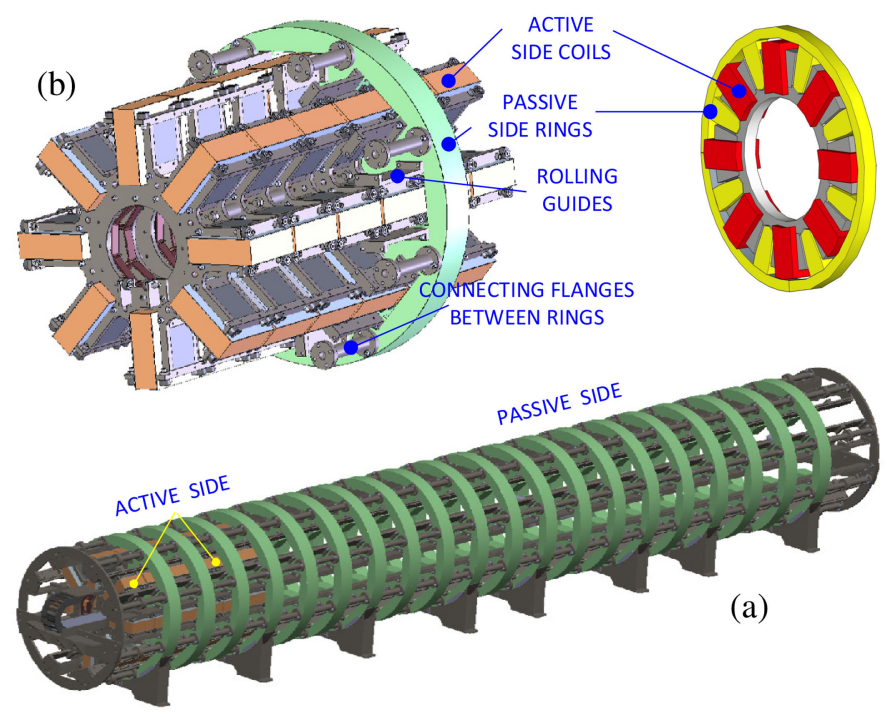

Fig. 10. (a) General lay-out of the AMSRM prototype for the Sea Titan Project (b) Detail view of the Passive and Active Sides, identifying the main components regarding the machine sketch in Figure 5(a).

\section{B. AMSRM Design}

Once the initial dimensions were selected, a 3D engineering design was performed [22] and validated with the required calculations that included thermal and mechanical computations to, primarily, verify the structural elements.

Also for the design, the generator (shown in Fig. 10) is divided into: a) The Passive Side, which is formed by magnetic iron rings with eight poles each. They are separated by flanges and spacers, on top of which the rolling guides for the moving side are placed b) The Active Side with two modules of a 3-phase AMSRM arrangement as shown in Fig. 5(b), to constitute two independent AMSRMs which can be fed as a motor and as a generator for testing the machine in steady conditions.

\section{Final Remarks}

The AMSRM is now starting to be manufactured and after it will be tested at CIEMAT premises, where both static and dynamic tests will be performed, driving the generator module with the motor module in a back-to-back configuration [23][25]. As also part of the Sea Titan Project, the consortium is developing a conceptual study of a Superconducting Switched Reluctance Machine, based on $\mathrm{MgB}_{2}$ wire. It is foreseen that increasing the magnetic field and current density values, will allow raising the specific force by a factor in between five to ten.

\section{CONCLUSION}

Heaving Point Absorbers are consolidated candidates (and probably also the best option) as Wave Energy Converters. To increase their harvesting capability, high specific force PTOs are required with capability for producing vector forces with Active and Reactive components. In this regard, the authors are developing a prototype of a new Azimuthal Switched Reluctance Machine in the framework of the Sea Titan H2020 Project. At this stage, the machine is fully calculated and designed and soon will start its fabrication and subsequent testing in a back-to-back configuration. A superconducting alternative will also be studied in the framework of the Project. 


\section{REFERENCES}

[1] "Energy roadmap 2050" [Online]. Available: https://ec.europa.eu/energy/ sites/ener/files/documents/2012_energy_roadmap_2050_en_0.pdf. Accessed on: May 14, 2020

[2] "SET Plan - Declaration of Intent on Strategic Targets in the context of an Initiative for Global Leadership in Ocean Energy", [Online]. Available: https://setis.ec.europa.eu/system/files/integrated_setplan/declaration_of_intent_ocean_0.pdf. Accessed on: May 14, 2020.

[3] "SEA-TITAN: Surging Energy Absorption Through Increasing Thrust And efficieNcy | SEA-TITAN Project | H2020 | CORDIS | European Commission." [Online]. Available: https://cordis.europa.eu/project/id/764014/ es. Accessed on: May 14, 2020

[4] I. López, J. Andreu, S. Ceballos, I. Martinez de Alegría, and I. Kortabarria, "Review of wave energy technologies and the necessary power equipment," Renewable Sustain. Energy Rev., vol. 27, pp. 413-434, 2013.

[5] J. Brooke, Wave Energy Conversion. Amsterdam, The Netherlands: Elsevier, 2003.

[6] B. Drew, A. R. Plummer, and M. N. Sahinkaya, "A review of wave energy converter technology," Proc. Inst. Mech. Eng., Part A: J. Power Energy, vol. 223, pp. 887-902, Dec. 2009.

[7] "Wave developers: EMEC: European Marine Energy Centre." [Online]. Available: http://www.emec.org.uk/marine-energy/wave-developers/. Accessed on: May 14, 2020.

[8] D. Magagna R. Monfardini, and A. Uihlein, "JRC Ocean Energy Status Report 2016 Edition," Publications Office of the European Union, 2016. doi: 10.2760/509876.

[9] M Lafoz, M. Blanco, P. Concha, G. Navarro, C. Vázquez, and L. García-Tabarés, "Study of the Dynamics and Functionality of a Wave Energy Converter," VERTICES- CIEMAT, vol. 24, pp. 3136, 2015. [Online]. Available: http://www.ciemat.es/vertices/vertices242015/Vertices24/pdf/Vertices-24.pdf

[10] M. Alves, "Wave-to-wire modelling of WECs," A. Pecher, J. Kofoed. eds., Handbook of Ocean Wave Energy. Ocean Engineering \& Oceanography, vol 7. Springer, Cham, pp. 261-287, 2017.

[11] L. Hai, "Modeling wave power by equivalent circuit theory," Uppsala Doctoral Thesis, Department of Engineering Sciences, Electricity, Uppsala Univ., Uppsala, SWEDEN, 2015.

[12] L. Huang, M. Chen, L. Wang, F. Yue, R. Guo, and X. Fu, "Analysis of hybrid field-modulated linear generator for wave energy conversion," IEEE Trans. Appl. Supercond., vol. 28, no. 3, Apr. 2018, Art. no. 0601205.

[13] J. Zhang, H. Yu, Q. Chen, M. Hu, L. Huang, and Q. Liu, "Design and experimental analysis of AC linear generator with Halbach PM arrays for direct-drive wave energy conversion," IEEE Trans. Appl. Supercond., vol. 24, no. 3, Jun. 2014, Art. no. 0502704.
[14] L. Huang, B. Hu, M. Hu, C. Liu, and H. Zhu, "Research on primary excitation fully superconducting linear generators for wave energy conversion," IEEE Trans. Appl. Supercond., vol. 29, no. 5, Aug. 2019, Art. no. 5203405.

[15] J. Prudell, M. Stoddard, E. Amon, T. K. A. Brekken, and A. von Jouanne, "A permanent-magnet tubular linear generator for ocean wave energy conversion," IEEE Trans. Ind. Appl., vol. 46, no. 6, pp. 2392-2400, Nov.-Dec. 2010.

[16] T. Xia, H. Yu, R. Guo, and X. Liu, "Research on the field-modulated tubular linear generator with quasi-halbach magnetization for ocean wave energy conversion," IEEE Trans. Appl. Supercond., vol. 28, no. 3, Apr. 2018 Art. no. 5206105.

[17] H. Polinder, E. C. Damer, and F. Gardner, "Linear PM generator system for wave energy conversion in the AWS," IEEE Trans. Energy Convers., vol. 19 , no. 3, pp. 583-589, Sep. 2004.

[18] M. A. Müller, "Electric generators for direct drive wave energy converters," IEE Proc. Gener. Transmiss. Distrib., vol. 149, no. 4, pp. 446-456, Jul. 2002.

[19] T. J. Lucas and M. M. Pinilla, "Switched reluctance linear motor/generator," WO/2008/058688, 2008. [Online]. Available: https: //patentscope. wipo.int/search/en/detail.jsf?docId=WO2008058688/. Accessed on: May 14, 2020.

[20] M. Blanco, M. Lafoz, G. Pinilla, L. Gavela, L. García-Tabarés, and A Echeandía, "Electric linear generator to optimize a point absorber wave energy converter," in 3rd Int. conf. exhibition Ocean Energy, ICOE 2010 2010, pp. 1-5. [Online]. Available: https://www.icoe-conference.com/ publication/electric_linear_generator_to_optimize_a_point_absorber_ wave_energy_converter/. Accessed on: May 14, 2020.

[21] L. García-Tabarés et al., "Concept \& calculations of the AMSRM01," Internal Note. CIEMAT, 2018.

[22] L. García-Tabarés et al., "Concept \& design of the AMSRM01," Internal Note. CIEMAT, 2019.

[23] M. Blanco, M. Lafoz, G. Pinilla, L. Gavela, L. Garcia-Tabarés, and A. Echeandía, "Laboratory testing schema for linear generators used in ocean wave energy conversion," in Proc. 11th World Renewable Energy Conf., 2010, pp. 875-880.

[24] M. Blanco, M. Lafoz, and L. García-Tabarés, "Laboratory tests of linear electric machines for wave energy applications with emulation of wave energy converters and sea waves," in Proc. 14th Eur. Conf. Power Electron. Appl., 2011.

[25] M. Santos-Herrán, M. Lafoz, M. Blanco, L. Gavela, and L. García-Tabarés, "Testing a full-scale PTO based on a switched reluctance linear generator for wave energy conversion," in 4th Int. Conf. Ocean Energy (ICOE2012), 2012. pp. 1-5. [Online]. Available: https://www.icoeconference.com/publication/testing_of_a_full_scale_pto_based_on_a_ switched_reluctance_linear_generator_for_wave_energy_conversion/ 